\section{Plagiarism? No, we're just borrowing better English}

\section{SIR - The accusations made by arXiv that my colleagues and I have plagiarized the works of others, reported in your News story 'Turkish physicists face accusations of plagiarism' (Nature 449, 8; 2007) are upsetting and unfair. \\ It's inappropriate to single out my colleagues and myself on this issue. For those of us whose mother tongue is not English, using beautiful sentences from other studies on the same subject in our introductions is not unusual. I imagine that if all articles from specialist fields of research were checked, similarities with other texts and papers would easily be found. In my case, I aimed to cite all the references from which I had sourced wording enough to pass muster, making it more difficult will at least discourage the lazier offenders. \\ As journals should welcome eliminating plagiarism at the preprint stage before publication, they could support the effort by giving the arXiv site search access to their own full-text databases. \\ John Bechhoefer \\ Department of Physics, Simon Fraser University, Burnaby, British Columbia V5A 156, Canada \\ Need to strike balance with industry-academia rules} information, although I may have missed some of them.

Borrowing sentences in the part of a paper that simply helps to better introduce the problem should not be seen as plagiarism. Even if our introductions are not entirely original, our results are - and these are the most important part of any scientific paper.

In the current climate of 'publish or perish', we are under pressure to publish our findings along with an introduction that reads well enough for the paper to be published and read, so that our research will be noticed and inspire further work.

Ihsan Yilmaz

Physics Department, Çanakkale Onsekiz Mart University, Canakkale, Turkey

\section{Plagiarism: text-matching program offers an answer}

SIR - The removal of almost 70 papers from the arXiv server on suspicion of plagiarism is dismaying (Nature 449, 8; 2007). But, in a similar way to that currently being tested by the cooperative group of publishers CrossRef (Academic accused of living on borrowed lines' Nature 448, 632-633; 2007), the search technology that led to this removal could be used to reduce future problems.

Every paper submitted to arXiv could be examined by a search engine that looks for overlap or correlation with all previous arXiv submissions. If enough of a match is found, a message could be sent to the submitter, listing the work(s) in which similarities have been detected. Should the submitter wish to proceed with their submission, the program would notify the editorial board and trigger an automatic review. The submitter would also be given the chance to explain that the flagged papers were not copied or that the copying was for some reason legitimate.

Such a system would address the problem of plagiarism only among papers published in
arXiv, but apparently that would already be an improvement. And although plagiarists might opt to copy and translate from foreign-language journals, or simply alter

SIR - It is appropriate to ask why universities permit alliances with industry, given that conflicts of interest can result. But your Editorial 'California dreaming' (Nature 448, 388 ; 2007) and your News story 'California campuses resist industry restrictions' (Nature 448,394 ; 2007), questioning the commitment of the University of California's campuses to regulate conflicts of interest, overlook the efforts that the campuses are making to address the issue, as well as the benefits that some collaboration can bring to public health.

Under guidelines currently implemented at the University of California, Los Angeles (UCLA; see http://dgsom.healthsciences. ucla.edu/administration/guidelinesMain), all marketing materials, including free lunches and other gifts from the pharmaceutical industry, are banned. Industry representatives are allowed to visit only by appointment and even then, only outside patient-care areas.

Faculty at other campuses have proposed greater restrictions, including clamping down on the granting of money from industry to some faculty members. Although such restrictions would remove one source of bias, they would also eliminate the benefits to public health of some alliances with industry. Breakthrough treatments are increasingly the product of academic collaboration with the pharmaceutical industry. Industry usually takes the lead in developing new medications or devices, but when academic researchers have the opportunity to examine cuttingedge treatments, they can learn more about root causes of illness and lay the foundations for even more effective treatments.

We don't expect any one set of policies to immunize academic researchers from bias or conflicts of interest. What is needed is the kind of tripartite policy that we have already developed at UCLA: the elimination of practices (such as free lunches) that add little to the academic mission but may introduce conflicts of interest; the regulation of practices (such as research grants) that add to the academic mission but may be sources of conflicts of interest; and the education of faculty, staff and trainees on sources of bias and conflicts of interest in academic medicine, to enable them to maintain the highest ethical standards.

Andrew Leuchter, Gerald S. Levey

Office of the Dean, David Geffen School of Medicine, UCLA Center for the Health Sciences, Los Angeles, California 90095-7035, USA

\section{Biosafety risk in health lab move to central London}

SIR - The recent outbreak of foot-andmouth virus around the Pirbright animalhealth laboratory in Surrey should dissuade the UK Medical Research Council from pursuing plans to move the National Institute for Medical Research (NIMR) from its semi-rural campus to the centre of London.

The expertise and facilities of the NIMR, which are among the world's best, are vital to combat future infectious diseases, and are a key component of national and international biosecurity. Research carried out at the NIMR includes studies on emerging pandemic viruses, such as avian influenza (H5N1), which are grown in level-4 containment facilities.

The NIMR has a superb safety record. However, the recent crisis at Pirbright is a reminder that accidents happen. The current Mill Hill site is excellent for minimizing secondary risk. If the NIMR is moved to central London, the consequences of containment failure would be horrific. A three-kilometre exclusion zone, as used in the recent foot-and-mouth epidemic, would reach 10 Downing Street and quarantine most of the UK government's decisionmakers. A ten-kilometre surveillance zone would affect all of central London.

Kings Cross, Euston and St Pancras railway stations, used by several million passengers each week, are five minutes' walk from the proposed NIMR site. After St Pancras becomes the London terminus for Eurostar in November, an escaped pathogen could reach Paris and Brussels within two hours. The first duty of government is security: the NIMR should stay at its present site.

Ellen Nisbet

Department of Biochemistry,

University of Cambridge,

Tennis Court Road, Cambridge CB2 1QW, UK

Contributions to Correspondence may be submitted to correspondence@nature.com. They should be no longer than $\mathbf{3 0 0}$ words; ideally shorter. Published contributions are edited. We welcome comments at Nautilus (http://blogs.nature.com/nautilus). 